\title{
Analysis of Calendar Effects: Day-of-the-Week Effect on the Stock Exchange of Thailand (SET)
}

\author{
Phaisarn Sutheebanjard and Wichian Premchaiswadi
}

\begin{abstract}
According to the Efficient Market Hypothesis (EMH), a stock's return is indifferent to a given trading day. But the day of the week effect phenomenon produces a different return for each day in the week. This is an abnormal return which can affect investors in deciding an investment strategy and portfolio management. This study examines the day of the week effect on stock market returns and the volatility of the Stock Exchange of Thailand (SET) index in order to know whether this anomaly exists or not. An experiment was conducted by using the daily SET Index data of 1,040 days from 4 January 2005 to 31 March 2009. The data on each day of the week was tested by applying the same prediction function. The prediction function incorporates important economic factors such as the Dow Jones index, the Nikkei index, the Hang Seng index and the domestic Minimum Loan Rate (MLR). The tuning coefficients of each factor in this research were calculated by using the two-membered Evolution Strategies (ES) technique. The results provide empirical evidence that day-of-the-week has a significant effect on the SET index with the highest percent of prediction error on Monday and the lowest percent of prediction error on Friday.
\end{abstract}

Index Terms-Calendar effects, Day-of-the week effect, Stock Exchange of Thailand, Evolution Strategies

\section{INTRODUCTION}

An interesting area of research related to stock market returns is the presence of calendar anomalies. In recent years the testing for market anomalies on stock returns has become an active field of research in empirical finance. Calendar effects are cyclical anomalies on returns in the financial market, where the cycle is based on the calendar. The most important calendar anomalies are the January effect and the day-of-the-week effect. The January Effect (also known as the turn-of-the-year effect or the January anomaly) was first observed in 1983 by Keim [19]. He noted that the average risk-adjusted return for a portfolio of small firms' stocks is large in January and much smaller for the rest of the year. The January effect is said to affect small caps more than mid or large caps.

The day-of-the-week effect (also known as the weekend effect) refers to the tendency of stocks to exhibit relatively large returns on Fridays compared to those on Mondays. The studies on day-of-the-week effect have been ongoing since 1930 when Kelly [1] revealed the existence of a Monday effect on the US markets where the returns turned out to be negative. The day of the week patterns have been

Graduate School of Information TechnologySiam University Bangkok 10163, Thailand investigated extensively in different markets [2-7]. The average daily return of the market is not the same for each day of the week. The day of the week effect phenomenon resulted in a different return for each day of a week. This phenomenon of return can affect investors in deciding investment strategy, portfolio selection, and profit management.

There are some researches on the day-of-the-week effects for the Stock Exchange of Thailand. Their findings support the notion that stock returns depend on the day of the week. But there are different day of the week patterns. Some researches results indicated that the returns are negative, on average, on Monday [4- 5], and other indicated that Monday has a significant positive return on average [6]. The purpose of this research is to present evidence on the day-of-the-week effects for the Stock Exchange of Thailand by applying a prediction function to each day in a week and evaluating the percent of error. The important factors that were used to forecast the SET index in the prediction function [15] include the Dow Jones (New York), the Nikkei (Japan), the Hang Seng (Hong Kong) and the Minimum Loan Rate (MLR) from the Bank of Thailand. The tuning coefficients of each factor in this research were calculated by using the two-membered Evolution Strategies (ES) technique.

The remainder of this paper is organized as follows. Section 2 provides a brief description of the Stock Exchange of Thailand. Section 3 explains the data collected and the methodology utilized. The empirical findings are reported in Section 4 , and the final section provides a summary of the paper.

\section{BACKGRound on THE StOck ExchANGE OF THAILAND}

The Thai stock market in Thailand officially started trading on April 30, 1975. The number of listed companies on the Stock Exchange of Thailand increased from 16 in 1975 to 476 in 2008 . And the total market capitalization increased from 1,522.92 million baht at the end of 1975 to 3.57 billion baht at the end of 2008. The index of the Stock Exchange of Thailand is called the SET Index. The SET Index is a composite market capitalization-weighted price index which compares the current market value (CMV) of all listed common stocks with its market value on the base date of April 30, 1975 (Base Market Value or BMV), which was when the stock market was established. The initial value of the SET index on the base date was set at 100 points. The formula of the SET index calculation as shown in (1)

$$
\text { SET Index }=\frac{\text { Current Market Value x } 100}{\text { Base Market Value }}
$$

The SET index movement is dependent on both global and 
domestic economic factors [8-15]. Since countries are linked together, movement on one stock market may have an impact on other stock markets. Naturally, the Thai stock market has unique characteristics, so the factors influencing the prices of stocks traded in this market are different from the factors influencing other stock markets [14]. An example of factors that influence the Thai stock market are foreign stock indexes, the value of the Thai Baht, the price of oil, the price of gold, the Minimum Loan Rate (MLR) and many others [8, 9, 10, 11, $12,13]$. There were some researchers that used these factors to forecast the Stock Exchange of Thailand (SET) index such as Tantinakom [8] who used trading value, trading volume, interbank overnight rate, inflation, net trading value of investment, value of the Thai Baht, price earning ration, the Dow Jones index, the Hang Seng index, the Nikkei index, the Straits Times Industrial index and the Kuala Lumpur Stock Exchange Composite index. In 2000, Khumpoo [9] used the Dow Jones index, the price of gold, the Hang Seng index, the exchange rate of the Japanese yen and the Thai baht, the Minimum Loan Rate (MLR), the Nikkei index, the price of oil, the Straits Times Industrial index and the Taiwan weighted index. In 2004, Chotasiri [10] used the interest rate of Thailand and the USA, the exchange rate of USD, JPY, HKD and SKD, the stock exchange indices of USA, Japan, Hong Kong and Singapore, the consumer price index, and the price of oil. In 2005, Chaereonkithuttakorn [11] used United State stock indices including the Nasdaq index, the Dow Jones index and the S\&P 500 index. In 2005, Rimcharoen et al. [12] used the Dow Jones index, the Nikkei index, the Hang Seng index, the price of gold and the Minimum Loan Rate (MLR). In 2007, Worasucheep [13] used the Minimum Loan Rate (MLR), the exchange rate of the Thai Baht and the US dollar, daily effective over-night federal fund rates in the USA, the Dow Jones index and the price of oil. In 2008, Chaigusin et al. [14] used the Dow Jones index, the Nikkei index, the Hang Seng index, the price of gold, the Minimum Loan Rate (MLR) and the exchange rate of the Thai Baht and the US dollar. The common factors that researchers used to predict the SET index are summarized in table I.

In 2005, Rimcharoen, et al. [12] used Adaptive Evolution Strategies to predict the Stock Exchange of Thailand index for the period of January 2003 to December 2004. The economic factors used in their experiment were the Dow Jones index, the Nikkei index, the Hang Seng index, the price of gold and the MLR. The experimental results show that their method can be used to forecast the Stock Exchange of Thailand index with an error less than 3\%. The Function used by Rimcharoen et al. as shown in (2).

TABLE I.IMPACT FACTORS TO STOCK EXCHANGE OF THAILAND INDEX

\begin{tabular}{|c|c|c|c|c|c|c|c|}
\hline & $\begin{array}{c}\text { Tantinakom } \\
1996[8]\end{array}$ & $\begin{array}{c}\text { Khumyoo } \\
2000[9]\end{array}$ & $\begin{array}{l}\text { Chotasiri } \\
2004[10]\end{array}$ & $\begin{array}{c}\text { Chaereonkithuttakorn } \\
2005 \text { [11] }\end{array}$ & $\begin{array}{c}\text { Rimcharoen } \\
\text { el al. 2005 } \\
{[12]}\end{array}$ & $\begin{array}{c}\text { Worasucheep } \\
2007[13]\end{array}$ & $\begin{array}{c}\text { Sutheebanjard } \\
\text { and } \\
\text { Premchaiswadi } \\
2009[15]\end{array}$ \\
\hline Nasdaq Index & & & & $\mathrm{x}$ & & & \\
\hline Dow Jones Index & $\mathrm{x}$ & $\mathrm{x}$ & $\mathrm{x}$ & $\mathrm{x}$ & $\mathrm{x}$ & $\mathrm{x}$ & $\mathrm{x}$ \\
\hline S\&P 500 Index & & & & $\mathrm{x}$ & & & \\
\hline Nikkei Index & $\mathrm{x}$ & $\mathrm{x}$ & $\mathrm{x}$ & & $\mathrm{x}$ & & $\mathrm{x}$ \\
\hline Hang Seng Index & $\mathrm{x}$ & $\mathrm{x}$ & $\mathrm{x}$ & & $\mathrm{x}$ & & $\mathrm{x}$ \\
\hline $\begin{array}{l}\text { Straits Times } \\
\text { Industrial Index }\end{array}$ & $\mathrm{x}$ & $\mathrm{x}$ & $\mathrm{x}$ & & & & \\
\hline USD & & $\mathrm{x}$ & $\mathrm{x}$ & & & $\mathrm{x}$ & \\
\hline JPY & & $\mathrm{x}$ & $\mathrm{x}$ & & & & \\
\hline HKD & & & $\mathrm{x}$ & & & & \\
\hline SKD & & & $\mathrm{x}$ & & & & \\
\hline Gold price & & $\mathrm{x}$ & & & $\mathrm{x}$ & & \\
\hline Oil price & & $\mathrm{x}$ & $\mathrm{x}$ & & & $\mathrm{x}$ & \\
\hline MLR & & $\mathrm{x}$ & & & $\mathrm{x}$ & $\mathrm{x}$ & $\mathrm{x}$ \\
\hline
\end{tabular}

Denote USD is the exchanges rates of the Thai Baht and the US dollar

JPY is the exchanges rates of the Thai Baht and Japanese Yen

where $(\mathrm{t})$ is today and $(\mathrm{t}-1)$ is yesterday.

HKD is the exchanges rates of the Thai Baht and Hong Kong dollar

SKD is the exchanges rates of the Thai Baht and Singapore dollar

$$
\begin{aligned}
& \operatorname{SET}_{(\mathrm{t})}=2.3645+5.5208 \sin ^{3}\left[0.3138_{(\mathrm{t}-1)}\right]- \\
& 1.5430 \operatorname{hangseng}_{(\mathrm{t}-1)} /-5.2054 \mathrm{mlr}_{(\mathrm{t}-1)}+ \\
& 2.8360 \cos ^{2}\left[0.6246_{(\mathrm{t}-1)}\right] * \\
& 4.6811 \sin \left[0.3651_{(\mathrm{t}-1)}\right]- \\
& 1.5380 \cos ^{3}\left[0.7522_{(\mathrm{t}-1)}\right]-1.1618 \cos ^{3}\left[0.7724_{(\mathrm{t}-1)}\right. \\
& ]+ \\
& 3.3228 \sin ^{3}\left[1.5317_{(\mathrm{t}-1)}\right]- \\
& 2.4620 \cos \left[0.6676_{(\mathrm{t}-1)}\right]^{*} \\
& 2.3144 \mathrm{mlr}_{(\mathrm{t}-1)}
\end{aligned}
$$

They have eventually found that the SET index can be adequately explained by only two major factors, the Hang Seng index and the MLR as shown in (3) and the graph as shown in Fig. 1.

$$
\operatorname{SET}_{(t)}=\frac{-1.5430 \text { hangseng }_{(t-1)}}{-5.2054 m \mathrm{mr}_{(t-1)}}
$$

In 2008, Chaigusin, et al. presented the graph of the forecasted SET index that were calculated from (3) by using the data from January 2005 to December 2006 compared to the actual SET index as shown in Fig. 2. 


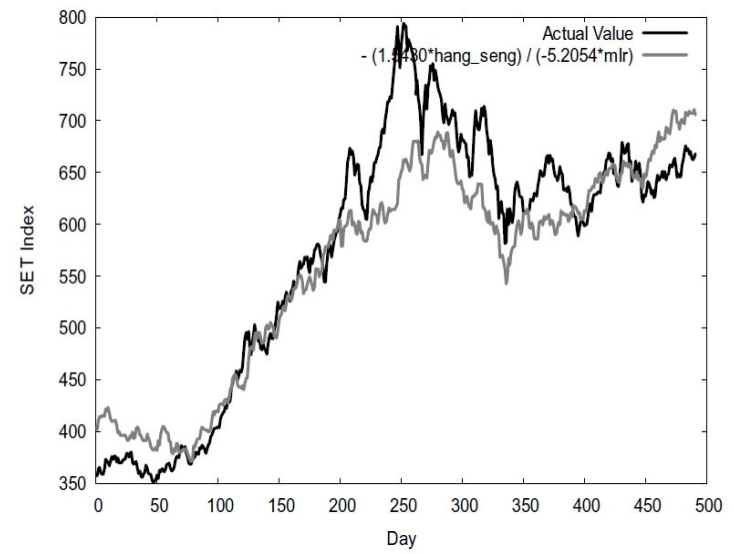

Fig. 1: The graph of SET Index prediction versus actual SET index during 2003-2004 against equation (3) [12]

It can be implied from these two figures that the SET index can be reasonably described by the Hang Seng index and the MLR in the year 2003 and 2004 but not in 2005 and 2006. This is because the data from the first 420 days during 2003 to 2004 was used as training data [12], therefore the SET index is explained reasonably well by the relationship (-1.5430HangSeng)/(-5.2054MLR) for that period.

In 2009, Sutheebanjard and Premchaiswadi [15] applied $(1+1)$ Evolution Strategies to predict the SET index during the periods of January 2003 to December 2004 and January 2005 to December 2006. The four factors used in the prediction function were the Dow Jones index, the Nikkei Index, the Hang Seng index and the MLR as shown in (4).

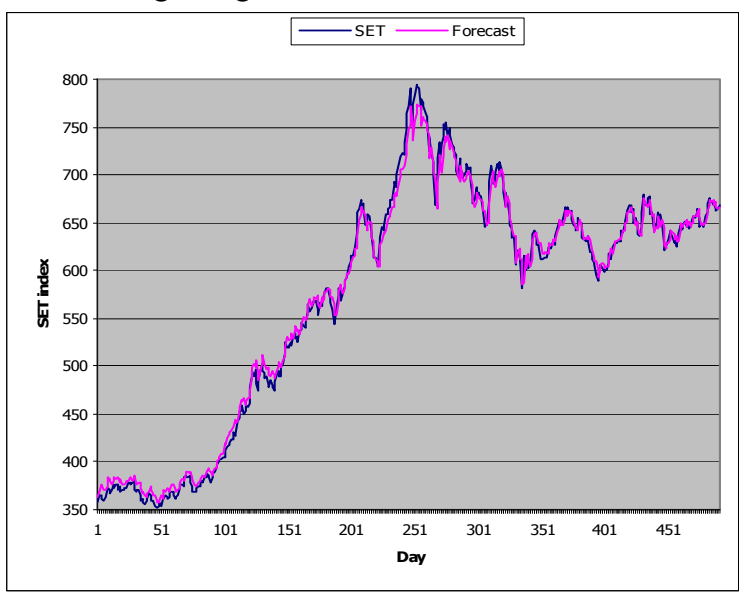

Fig. 3:The graph of SET Index prediction versus actual SET index during 2003-2004 against equation (4)[15]

\section{DATA AND Methodology}

In predicting the SET index, this research used the function of Sutheebanjard and Premchaiswadi [15] as shown in (5) that is composed of global and domestic factors, namely; Dow Jones index (New York), Nikkei index (Japan), Hang Seng index (Hong Kong), domestic Minimum Loan Rate (MLR) and SET index (Thailand) itself. The experimental data were obtained from the Bank of Thailand. Daily data on the SET index from January 2004 to December 2004 were used for the training phase and data from January 2005 to March 2009 was used for the testing phase.

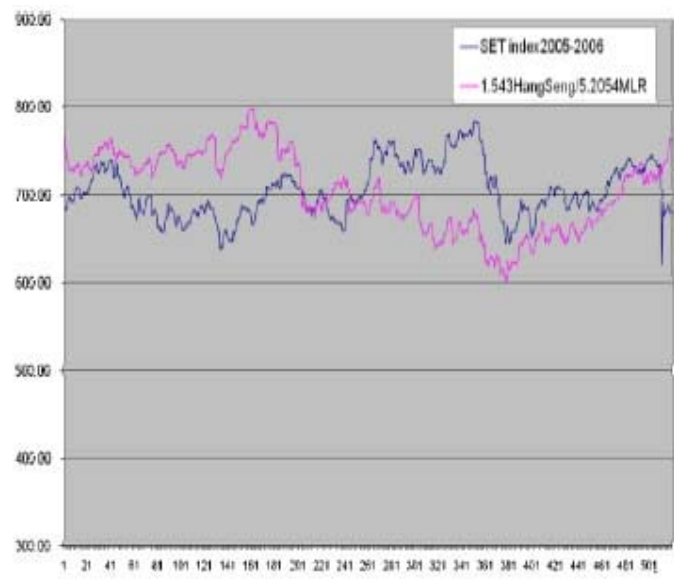

Fig. 2: The graph of SET index prediction versus actual SET index during 2005-2006 against (-1.5430hangseng)/(-5.2054mlr) [14]

The experimental results show that the prediction function of Sutheebanjard and Premchaiswadi predicted the SET index with less than $2 \%$ error for both periods. The graph of the SET index prediction during the period of January 2003 to December 2004 is shown in Fig. 3, and the index prediction during the period of January 2005 to December 2006 as shown in Fig. 4.

$S E T_{(t)}=0.86 S E T_{(t-1)}+0.021008 \times\left(\left(0.632529 D J_{(t-1)}+\right.\right.$

$$
\begin{aligned}
& \left.0.317615 \mathrm{NK}_{(t-1)}+0.156434 H S_{(t-1)}\right) / \\
& \left.0.509522 M L R_{(t-1)}\right)
\end{aligned}
$$

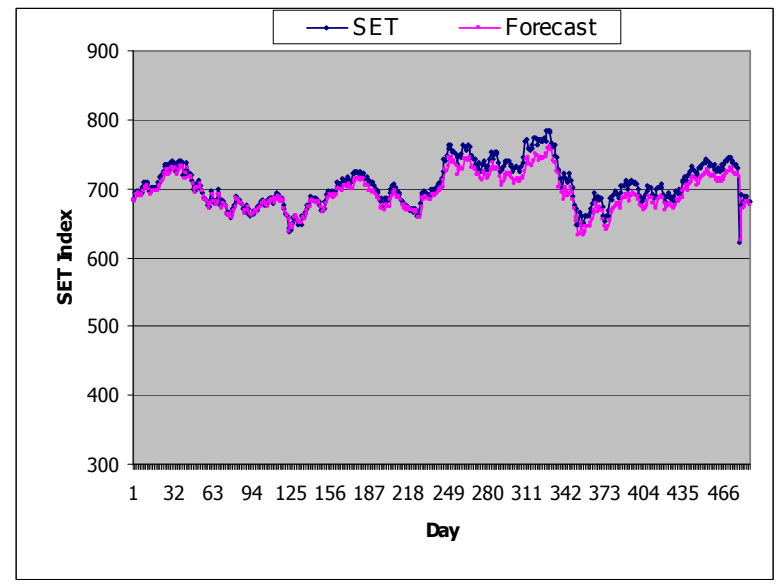

Fig. 4: The graph of SET index prediction versus the actual SET index during 2005-2006 [15]

$$
\begin{gathered}
\operatorname{SET}_{(t)}=a_{0} S E T_{(t-1)}+a_{1}\left(\frac{a_{2} D J_{(t-1)}+a_{3} N K_{(t-1)}+a_{4} H S_{(t-1)}}{a_{5} M L R_{(t-1)}}\right) \\
\text { where } a_{0}-a_{5} \text { denote coefficients. }
\end{gathered}
$$

$S E T$ is SET index (Thailand) $D J$ is Dow Jones index (New York) $N K$ is Nikkei index (Japan) $H S$ is Hang Seng index (Hong Kong) $M L R$ is Minimum Loan Rate (MLR)

The proposed method applied the $(1+1)$ Evolution Strategies $[16,17]$ in the coefficient tuning process, and training and testing the data were done for each individual day of the week. The intention of the research was to find patterns of the SET index movement that was possibly influenced by the day of the week. 
Evolution Strategies (ES) was introduced by Rechenberg [18]. Similar to Genetic Algorithms, Evolution Strategies (ES) are algorithms which imitate the principles of natural evolution as a method to solve parameter optimization problems. The concept is to use the principles of organic evolution processes as the rules for optimum seeking procedures. The $(1+1)$-ES is a simple mutation-selection scheme called two-membered ES. It is based upon a "population" consisting of one parent individual (a real valued vector), and one descendant, created by means of adding normally distributed random numbers with identical standard deviations. The resulting individual was evaluated by a fitness function and compared to its parent, and the better of both individuals survives to become the parent of the next generation, while the other one is discarded.

This research used the Mean Squared Error (MSE) as a fitness function in order to minimize the error of fitness between the prediction function and actual value as shown in (6).

$$
\begin{aligned}
& \text { MSE }=\frac{1}{n} \sum_{t=1}^{n}\left(g_{(t)}-f_{(t)}\right)^{2} \\
& \text { where } g_{(t)} \text { is an actual value. } \\
& \quad f_{(t)} \text { is a forecasted value } \\
& n \text { is the number of data points. }
\end{aligned}
$$

In controlling the search strategy, an adjustment of the standard deviation was considered and taken from the ratio of the better individual during the evolution process, referred to as the $1 / 5$ success rule [18] as shown in (7).

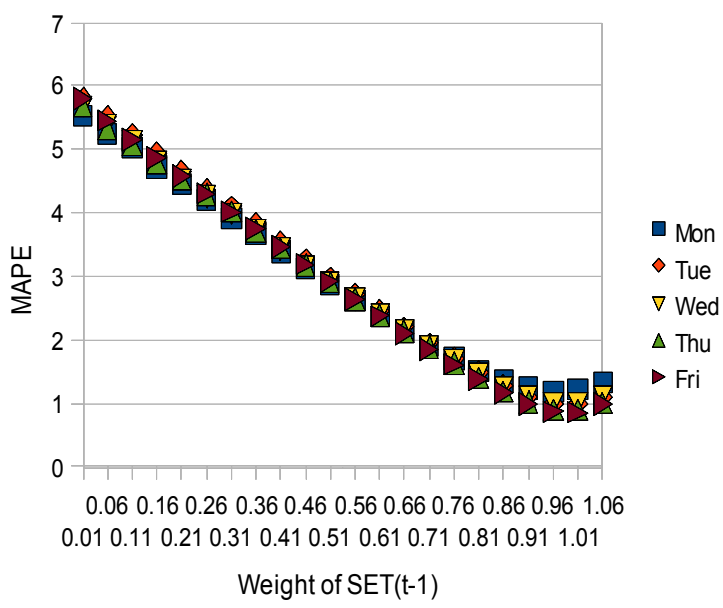

Fig. 5: The lowest MAPE of each single day from (5) at different weight of SET index $(\mathrm{t}-1)$ scale from $0.01-1.06$

$$
\sigma^{\prime}= \begin{cases}\sigma / 0.817 & \text { if }(p>1 / 5) \\ \sigma \cdot 0.817 & \text { if }(p<1 / 5) \\ \sigma & \text { if }(p=1 / 5)\end{cases}
$$

This research used the Mean Absolute Percentage Error (MAPE) to measure the error, which is the difference between the forecasted value and actual value. MAPE expresses the error as a percentage. MAPE is commonly used in quantitative forecasting methods because it produces a measure of relative overall fit. The absolute values of all the percentage errors are summed up and the average is computed. The MAPE function as shown in (8).

$$
\begin{aligned}
& M A P E=\frac{\sum_{t=1}^{n}\left|\frac{g_{(t)}-f_{(t)}}{g_{(t)}}\right|}{n} \times 100 \\
& \text { where } g_{(t)} \text { is an actual value. } \\
& f_{(t)} \text { is a forecasted value } \\
& n \text { is the number of data points. }
\end{aligned}
$$

\section{EXPERIMENTAL RESULTS}

In this experiment, the coefficients of (5) were computed using Evolution Strategies for 34,000 times on each individual day of the week. The lowest MAPE at each level of $a_{0}$ (weight of SET index $(t-1)$ ) from 0.01 to 1.06 were selected as shown in Fig. 5. And at each level of $a_{0}$ from 0.91 to 1.04 were selected as shown in Fig. 6 .

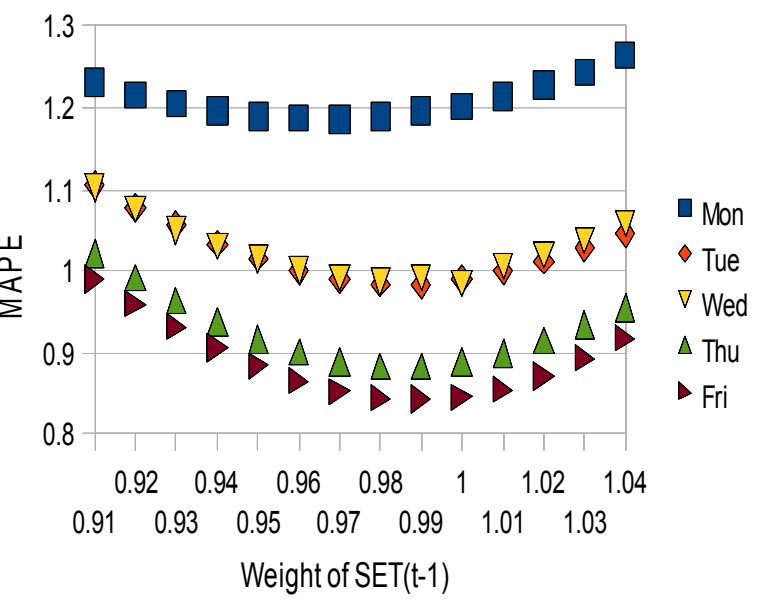

Fig. 6: The lowest MAPE of each single day from (5) at different weight of SET index(t-1) scale from 0.91-1.04

In Fig. 5, the MAPE of each individual day is nearly the same for almost every level of $a_{0}$ from 0.01-1.06. But Fig. 6 shows that at the finer scale of $a_{0}$ from 0.91-1.04, Monday has the highest MAPE and Friday has the lowest MAPE.

This study also tested the prediction function on all days in a week (Monday through Friday denoted as "Mon-Fri" in the figure). The result was compared to each individual day of the week as illustrated in Fig. 7. The MAPE from the test on all days in a week is in the middle of the graph, which indicates the average error. Therefore, it can be concluded that the prediction error on Monday is higher than average, on Tuesday and Wednesday the prediction errors are almost equal to the average and on Friday and Thursday the prediction errors are lower than the average. The details of 
data used to plot the graphs in Fig. 5-7 are shown in table II and III.

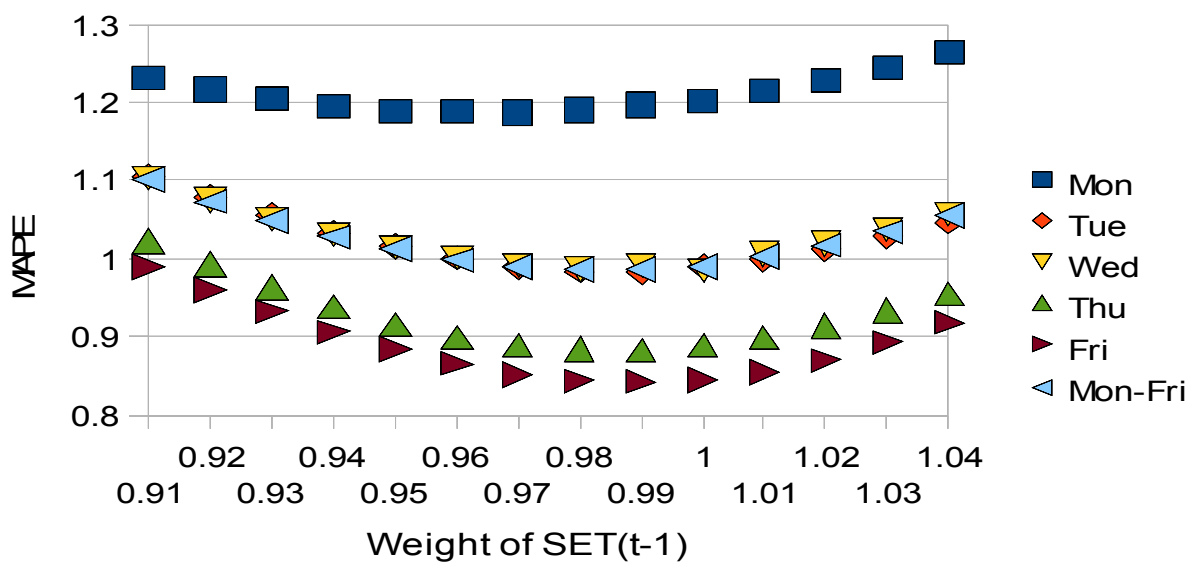

Fig. 7: The lowest MAPE of each single day compare to everyday (denote as "Mon-Fri") from equation 5 at different weight of SET index(t-1) scale from $0.91-1.04$

TABLE II. THE LOWEST MAPE OF EQUATION 5 AT DIFFERENT WEIGHT OF SET INDEX(T-1) SCALE FROM 0.01-1.06

\begin{tabular}{|c|c|c|c|c|c|c|}
\hline SET & Monday (\%) & Tuesday (\%) & Wednesday (\%) & Thursday (\%) & Friday (\%) & Monday-Fri day $(\%)$ \\
\hline 0.01 & 5.5246 & 5.7979 & 5.6805 & 5.6672 & 5.7985 & 5.8692 \\
\hline 0.06 & 5.2515 & 5.5215 & 5.3932 & 5.3373 & 5.4540 & 5.5857 \\
\hline 0.11 & 5.0228 & 5.2191 & 5.1308 & 5.0711 & 5.1483 & 5.2384 \\
\hline 0.16 & 4.7241 & 4.9332 & 4.8109 & 4.7958 & 4.8692 & 5.0262 \\
\hline 0.21 & 4.4582 & 4.6503 & 4.5312 & 4.5291 & 4.5835 & 4.7574 \\
\hline 0.26 & 4.1930 & 4.3670 & 4.2556 & 4.2918 & 4.3036 & 4.4127 \\
\hline 0.31 & 3.9142 & 4.1020 & 3.9799 & 4.0138 & 4.0130 & 4.1301 \\
\hline 0.36 & 3.6784 & 3.8204 & 3.7141 & 3.7232 & 3.7454 & 3.8930 \\
\hline 0.41 & 3.3926 & 3.5354 & 3.4352 & 3.4521 & 3.4621 & 3.6067 \\
\hline 0.46 & 3.1309 & 3.2698 & 3.1629 & 3.1777 & 3.1860 & 3.2766 \\
\hline 0.51 & 2.8769 & 2.9875 & 2.8983 & 2.9095 & 2.9152 & 3.0764 \\
\hline 0.56 & 2.6198 & 2.7203 & 2.6411 & 2.6444 & 2.6414 & 2.7164 \\
\hline 0.61 & 2.3771 & 2.4546 & 2.3854 & 2.3900 & 2.3733 & 2.4429 \\
\hline 0.66 & 2.1346 & 2.1993 & 2.1359 & 2.1319 & 2.1071 & 2.2507 \\
\hline 0.71 & 1.9107 & 1.9453 & 1.8980 & 1.8833 & 1.8519 & 1.9474 \\
\hline 0.76 & 1.7080 & 1.7124 & 1.6710 & 1.6388 & 1.6079 & 1.6823 \\
\hline 0.81 & 1.5129 & 1.4914 & 1.4581 & 1.3981 & 1.3838 & 1.4695 \\
\hline 0.86 & 1.3489 & 1.2846 & 1.2644 & 1.1892 & 1.1713 & 1.2670 \\
\hline 0.91 & 1.2318 & 1.1059 & 1.1022 & 1.0222 & 0.9894 & 1.1048 \\
\hline 0.96 & 1.1879 & 1.0004 & 1.0010 & 0.8997 & 0.8655 & 0.9984 \\
\hline 1.01 & 1.2141 & 0.9994 & 1.0059 & 0.8993 & 0.8543 & 1.0021 \\
\hline 1.06 & 1.3208 & 1.0974 & 1.1055 & 1.0102 & 0.9830 & 1.1103 \\
\hline
\end{tabular}

TABLE III. THE LOWEST MAPE OF EQUATION 5 AT DIFFERENT WEIGHT OF SET INDEX(T-1) SCALE FROM 0.91-1.04

\begin{tabular}{|c|c|c|c|c|c|c|}
\hline SET & Monday (\%) & Tuesday (\%) & Wednesday (\%) & Thursday (\%) & Friday (\%) & Monday-Fri day(\%) \\
\hline 0.91 & 1.2318 & 1.1059 & 1.1022 & 1.0222 & 0.9894 & 1.1007 \\
\hline 0.92 & 1.2158 & 1.0777 & 1.0756 & 0.9923 & 0.9595 & 1.0730 \\
\hline 0.93 & 1.2054 & 1.0562 & 1.0500 & 0.9632 & 0.9320 & 1.0486 \\
\hline 0.94 & 1.1957 & 1.0331 & 1.0309 & 0.9379 & 0.9062 & 1.0277 \\
\hline 0.95 & 1.1890 & 1.0154 & 1.0137 & 0.9160 & 0.8836 & 1.0119 \\
\hline 0.96 & 1.1879 & 1.0004 & 1.0010 & 0.8997 & 0.8655 & 0.9984 \\
\hline 0.97 & 1.1863 & 0.9898 & 0.9919 & 0.8890 & 0.8522 & 0.9902 \\
\hline 0.98 & 1.1900 & 0.9845 & 0.9856 & 0.8838 & 0.8439 & 0.9868 \\
\hline 0.99 & 1.1961 & 0.9832 & 0.9915 & 0.8831 & 0.8429 & 0.9869 \\
\hline 1.00 & 1.2020 & 0.9892 & 0.9844 & 0.8886 & 0.8455 & 0.9900 \\
\hline 1.01 & 1.2141 & 0.9994 & 1.0059 & 0.8993 & 0.8543 & 1.0020 \\
\hline
\end{tabular}




\begin{tabular}{|l|l|l|l|l|l|l|}
\hline 1.02 & 1.2272 & 1.0125 & 1.0197 & 0.9140 & 0.8704 & 1.0166 \\
\hline 1.03 & 1.2435 & 1.0285 & 1.0365 & 0.9339 & 0.8930 & 1.0346 \\
\hline 1.04 & 1.2648 & 1.0462 & 1.0575 & 0.9554 & 0.9181 & 1.0558 \\
\hline
\end{tabular}

\section{CONCLUSION}

The primary objective of this paper was to investigate the day-of-the-week effect on stock market returns and the volatility of the Stock Exchange of Thailand (SET) index for the period from 4 January 2005 to 31 March 2009, 1040 days in total. The analysis was conducted by applying Evolution Strategies. The results provide empirical evidence that the day-of-the-week effect was present in the Stock Exchange of Thailand (SET) returns data during the investigated period.

In this research, prediction functions were employed to predict the SET index on Monday, Tuesday, Wednesday, Thursday and Friday. The results show that the percent of error is highest on Monday and lowest on Friday. Thus, it can be concluded that the Day-of-the-Week had a significant effect on the Stock Exchange of Thailand index during the investigated period. Since this study provides evidence of the day-of-the-week effect on the Thai stock market, therefore it can be used by investors, in addition to other stock market analysis tools, to maximize their expected return by exploiting calendar anomalies in their portfolios as well as to forecast stock market trends, which can help them in their decision making process.

\section{REFERENCES}

[1] Kelly, F., "Why You Win or Lose: The Psychology of Speculation," Boston: Houghton Mifflin, 1930.

[2] Christos S. Savva, Denise R. Osborn and Len Gill, "The Day of the Week Effect in Fifteen European Stock Markets," Conference on High Frequency Finance. University of Konstanz paper, available at http://www.uni-konstanz.de/micfinma/conference/Files/ papers/Savva_Osborn_Gill.pdf

[3] Chiaku Chukwüogor-Ndu, "Stock Market Returns Analysis, Day-of-the-Week Effect, Volatility of Returns: Evidence from European Financial Markets 1997-2004," International Research Journal of Finance and Economics. 112-124, 2006

[4] Ravindra R. Kamath, Rinjai Chakornpipat and Arjun Chatrath, "Return distributions and the day-of-the-week effects in the stock exchange of Thailand," Journal of Economics and Finance. Volume 22, Numbers 2-3, June, 1998

[5] Hooi Hooi Lean, Russell Smyth and Wing-Keung Wong, "Revising Calendar Anomalies in ASIAN Stock Markets using A Stochastic Dominance Approach," Journal of Multinational Financial Management. Volume 17, April, 125-141, 2007

[6] Chris Brooks and Gita Persand, "Seasonality in Southeast Asian Stock Markets Some New Evidence on day-of-the-week Effects," Journal Applied Economics Letters, Volume 8, March, 2001

[7] Anwar, Yunita \& Mulyadi, Martin Surya, "The day of the week effects in Indonesia, Singapore, and Malaysia stock market," MPRA Paper, University Library of Munich, Germany, 2009

[8] Tantinakom, T. "Economic Factors Affecting Stock Exchange of Thailand Index," Master Thesis in Economics, Chiang Mai University, Chiang Mai, Thailand, 1996

[9] Khumyoo, C. "The Determinants of Securities Price in the Stock Exchange of Thailand," Master Thesis in Economics, Ramkhamhaeng University, Bangkok, Thailand, 2000

[10] Chotasiri, S. "The Economic Factors Affecting the Fluctuation of The Stock Exchange of Thailand Index," Master Thesis in Economics, Chiang Mai University, Chiang Mai, Thailand, 2004

[11] Chaereonkithuttakorn, K. "The Relationship between the Stock Exchange of Thailand Index and the Stock Indexes in the United States of America," Master Thesis in Economics, Chiang Mai University, Chiang Mai, Thailand, 2005
[12] Rimcharoen, S., Sutivong, D. \& Chongstitvatana, P. "Prediction of the Stock Exchange of Thailand Using Adaptive Evolution Strategies," Tools with Artificial Intelligence, 2005. ICTAI 05. 17th, 2005

[13] Worasucheep, Chukiat. "A New Self Adaptive Differential Evolution: Its Application in Forecasting the Index of Stock Exchange of Thailand," Evolutionary Computation, 2007. CEC 2007, 2007

[14] Chaigusin, S., Chirathamjaree, C. \& Clayden, J. "Soft computing in the forecasting of the stock exchange of Thailand (SET). Management of Innovation and Technology," ICMIT 2008. 4th, 2008

[15] Phaisarn Sutheebanjard and Wichian Premchaiswadi, "Factors Analysis on Stock Exchange of Thailand (SET) Index Movement," The 7th International Conference on ICT and Knowledge Engineering, ICTKE2009, Bangkok, Thailand, December 1-2, 2009.

[16] Back, T., Hoffmeister, F. and Schwefel, H.P. "A Survey of Evolution Strategies," Proceeding of the Fourth Conference on Genetic Algorithm, 1991

[17] Beyer, H.G. and Schwefel, H.P. "Evolution Strategies-A Comprehensive Introduction," Natural Computing. Vol. 1, Issue 1, 2002

[18] Rechenberg, I. "Evolutionsstrategie: Optimierung technischer Systeme nach Prinzipien der biologischen Evolution." Stuttgart: Frommann-Holzboog Verlag. 1973.

[19] Keim, Donald B. "Size-Related Anomalies and Stock Return Seasonality: Further Empirical Evidence," Journal of Financial Economics 12, 1983 